\title{
Does immigration undermine public support for integration in the European Union?
}

\author{
Dimiter Toshkov and Elitsa Kortenska*
}

Pre-print version. Final revision: January 14, 2015

\begin{abstract}
It is well established that negative attitudes towards immigrants are strongly associated with lower public support for European integration. But the impact of actual immigration levels on immigration attitudes is still contested. As a result, the relationship between immigration levels and EU public support remains uncertain from a theoretical point of view. We offer an empirical study of the link between immigration from the new EU member states from Central and Eastern Europe (CEE) and EU support at the regional level in Spain, France, Ireland and The Netherlands. The results of the analyses suggest that in all four countries immigration from CEE had negative effects on support for European integration in the host societies. In short, immigration seems to undermine integration, although internal migration within the EU is necessary for the successful functioning of its economic union and the future of political integration.
\end{abstract}

\section{Keywords}

anti-immigration attitudes, EU Enlargement, EU public support, European integration, Euroscepticism, immigration, labor mobility

*Dimiter Toshkov is Assistant Professor of Public Administration at Leiden University, The Netherlands (d.d.toshkov@cdh.leidenuniv.nl). Elitsa Kortenska is a PhD student at the Institute of Public Administration, Leiden University, The Netherlands. (e.g.kortenska@cdh.leidenuniv.nl). The authors would like to thank Lori Thorlakson, Nicole Lugosi, Theresa Kuhn, Anne Rasmussen, and the participants at the Ten Years On: Evaluating Eastern Enlargement ECPR Joint Session (10-15 April 2014, Salamanca, Spain) and the Seventh Pan-European Conference on the EU (57 June 2014, The Hague, The Netherlands) for helpful comments and suggestions. 


\section{Introduction}

Political, economic, and societal integration of democratic states, market economies, and liberal societies imply the free movement of people, capital, goods, and services. Short and long-term migration from one part of the integrating territory to another can alleviate asymmetric economic shocks (Mundell 1961, Silvia 2011), foster the development of common identities (Deutsch 1953, Scharpf 2013, but see Kuhn 2012), and speed up the emergence and diffusion of shared norms and ideas (Zürn and Checkel 2005). Integration requires and builds on internal migration to address social and economic challenges.

But at the same time, migration can undermine politically the process of integration. Citizens might not like the idea of welcoming newcomers from other parts of the union. Perceived cultural threats and/or competition for jobs, public services and social benefits can lead people in host nations to resent and oppose the arrival of immigrants. Crucially, fear and resentment can turn towards integration as such. Directly and through the actions of opportunistic political elites, negative public attitudes towards immigration spurred by rising numbers of immigrants can put limits to the free movement of persons, effectively halting the process of integration. In short, we have a paradox. While internal migration is necessary for economic and societal integration, it can act to subvert both through its unintended political effects.

We study this paradox in the context of the European Union (EU). The process of EU enlargement to the East (the preparations for which started already in the 1990s) spurred a significant level of migration from Central and Eastern Europe (CEE) to the old member states in Southern, Western, and Northern Europe (Gilpin et al. 2006, Friberg and Eldring 2013). The increasing presence and visibility of migrants from CEE coincided with a period of decreasing public support for European integration (Hooghe and Marks 2009), increasing levels of anti-immigration attitudes in Europe (Semyonov et al. 2006), and the rise of anti-immigration parties to the political scene in a number of countries (Mudde 2007).

In this paper, we hypothesize that internal migration should reduce public enthusiasm for (further) integration, that the effect should be most visible at the local/regional level, and that it should vary by country. Empirically, we explore the relationship between levels of immigration from CEE and public support for European integration at the local level in four 'old' EU members from Western and Southern Europe - France, Ireland, Spain, and The Netherlands. In order to obtain representative local level estimates of public attitudes towards integration, we look into the results of the referendums on the ill-fated European constitution in 2005 and and the Treaty of Lisbon in 2008. To the best of our knowledge, we offer the first empirical assessment of the impact of CEE immigration on EU public support.

We find that in all four countries we study a higher number of CEE immigrants registered in a region is associated with lower levels of support for further European integration, after controlling for potential confounders like economic conditions (unemployment), support for the governing parties, and levels of pre-existing immigration. In France, Ireland, and The Netherlands, the negative association is statistically significant.

Altogether, our empirical analyses suggest that in the case of the EU internal migration has indeed eroded support for integration during the first decade of the twenty-first century. While it is well known that at the individual level anti-immigration attitudes are linked with opposition to the EU (most recently, Boomgaarden et al. 2011), we demonstrate that real-world levels of immigration can fuel the former thus eroding the 
latter. In more practical terms, our findings raise the question whether the future of European integration is sustainable given the necessity of growing internal migration and the increasing reluctance of Western societies to put up with the presence of more immigrants, be they from their fellow EU member states or not.

\section{Immigration and public attitudes: contact, threat, and competition}

The research problem we pose in this article sits at the intersection of vast literatures spanning Political Science, Sociology, Social Psychology, European Studies, Political Geography, and other related disciplines. In this part of the article we will draw on these literatures to sketch a theoretical model of the interactions between immigration, integration, economic conditions and public attitudes. Our contribution is mostly in pulling threads of existing theoretical ideas together, and gauging their implications for the case of European integration. In fact, our main point is that since there are conflicting theoretical expectations about the potential impact of immigration levels on public attitudes towards immigration and integration, the empirical study of this link in the context of the EU gains scientific relevance and, indeed, urgency.

\subsection{Levels of immigration and anti-immigration attitudes}

The effect of the presence of immigrants on anti-immigration (xenophobic) attitudes and behaviors of the host population is theoretically and empirically contested. Sociologists and social psychologists have long studied inter-group contact and its impact. The hypothesis that contact with people from a different race or ethnic group will tend to decrease prejudice and negative predispositions and promote mutual understanding given some conditions (Allport 1954) receives some support, but it remains difficult to specify the conditions under which the positive effects will obtain (see a review in Pettigrew 1998). Most of the micro-mechanisms on which contact theory relies - e.g. learning and the formation of affective ties - require that there is direct and sustained personal contact which is unlikely to hold in the general case for immigration - few people from the local population would have direct and sustained contact with immigrants, so their attitudes and behaviours will be informed by a mixture of direct and indirect contact, hearsay, as well as images and frames provided by national and local media and state authorities.

Theoretically, the local presence of immigrants can easily magnify the anti-immigration hostility of the local population. The arrival of large groups of immigrants puts pressure on and increases competition for the public services in the area, like (social) housing, public administration, utilities, parking spaces, etc. It might lead to housing segregation, with those from the locals who can afford it, leaving the immigrant-targeted areas. The presence of immigrants might also increase crime and petty nuisances in the neighborhoods. Putnam (2007) for example shows that inter-personal trust declines with the ethnic heterogeneity of American neighbourhoods.

In fact, in addition to contact theory, an altogether different theoretical mechanism for the effect of the presence of an outgroup, like an immigration community, on the attitudes of the host group and inter-group relations has been proposed. The idea is that, rather than understanding, contact fosters competition. Under the loose label 'group threat theory', this mechanism has been studied theoretically (starting with 
Blalock 1967) and empirically (for example Scheepers et al. 2002, Semyonov et al. 2004, Wagner et al. 2006), but with inconclusive results.

For example, Manevska and Achterbeg (2011) find that perceived ethnic threat seems to be unrelated to the size of the (low-educated and non-Western) immigrant communities in the countries (p.9). But working with the same sample, Schneider (2008) finds that the size of non-Western immigrant communities has a nonlinear relationship with perceived ethnic threat: initially the link is positive but it flattens out and eventually is even reversed (p.62). Schlueter and Scheepers (2010) find an even more complex pattern of relationships in a study of the Dutch case. Objective immigrant group size is related with perceived group size, but not with the perceived level of group threat. But perceived threat is related to perceived outgroup size, disapproval of immigrants and discriminatory intentions.

According to McLaren (2003), intimate contact with minorities reduces preferences for expulsion of immigrants. The size of immigration to a country influences perceptions of threat, but not attitudes as such, and contact mediates the effect of outgroup size at the individual level. Schlueter and Wagner (2008) argue, based on data from the European Social Survey, that when we compare sub-national European regions, a larger size of immigrant population in the region increases perceived group threat and intergroup contact. An analysis based on instrumental variable estimation finds that in Austria the presence of immigrants has a quantitatively important and statistically significant negative impact on citizens' voting patterns at the neighborhood level (Halla et al. 2012). When looking at these relationships at the district level in Germany, Wagner et al. (2006) find that 'the proportion of ethnic minority members in a population is linked to a reduction of prejudice in the majority' (p.386). The precise level of aggregation used in the analysis seems to matter. Looking at the link between outgroup size and votes for the French Front National (FN), Della Posta (2013) concludes that the relationship changes depending on the level of analysis: 'At the department...level, large immigrant populations are associated with higher FN vote totals, while t the commune... level, however, large immigrant populations are instead associated with lower FN vole totals' (p.249). Sides and Citrin (2007) argue that 'symbolic' (cultural) predispositions have greater effect on immigration attitudes than economic dissatisfaction. They also show that people overestimate the size of immigrant communities living in their countries (p.487), and that the individuals who tend to overestimate the share of immigrants their country gets compared to others, tend to perceive more negative consequences from the presence of immigrants and to prefer lower levels of immigration to their country.

Altogether, it is difficult to form unidirectional hypotheses about the link between outgroup size (of immigrant communities) and anti-immigration attitudes and behaviors at the individual level, and even more so at an aggregate level. On balance, individuals who experience direct contact with immigrants might be less likely to have strong anti-immigrant dispositions, but the strength and even the direction of the link depends on characteristics of the outgroup member, the ingroup member, and the nature of the contact. Moving from the individual to a higher level of aggregation, the positive individual contact effects are likely to be trumped by the effects of immigration presence threat which in their turn are related to the subjective, and more weakly, to the objective size of the group. As few members of the host community would experience direct contact, the indirect effects of presence would start to dominate. 


\subsection{Anti-immigration attitudes and support for integra- tion}

While the link between outgroup size (immigration presence) and xenophobic attitudes of the host population is theoretically uncertain and empirical understudied in the context of the EU, the link between anti-immigration attitudes and public support for the EU is well-established. Altogether, individuals who disapprove, fear, and feel threatened by immigration are much more likely to oppose further European integration and to evaluate negatively the EU (De Vreese and Boomgaarden 2005, Boomgaarden et al. 2011). It should be noted however that concerns about immigration decrease not only support for the EU but political trust more generally (McLaren 2012).

Anti-immigration attitudes are related to general support for European integration, and to specific support for EU involvement in particular areas, like immigration policy (Luedtke 2005). Barbulescua and Beaudonnet (2014) find that in Italy concern about immigration is related to declining support for European integration and that the effect varies across regions with (total) immigration rates.

Anti-immigration attitudes are related to attitudes towards EU enlargement as well. Lubbers and Jaspers in particular argue that 'The low educated in particular would feature more nationalistic attitudes and consequently express stronger fears about deepening EU integration and increased immigration from new EU member countries.' (2011, p.25). Azrout et al. (2013) discover that having anti-immigrant attitudes strongly predicts opposition to the prospects of Turkish membership in the EU, and that average national opposition is related to the size of the Turkish immigrant community in the country.

The impact of anti-immigration attitudes is not confined to opinions, but influences voting decisions as well. For example, van Spanje and de Vreese (2011) discover that 'anti-immigration attitudes ma[d]e the leftist vote more Eurosceptic and the rightist vote even more so' (p.418) at the 2009 elections for the European Parliament. Similarly, in the context of national referendums on European issues, anti-immigrant attitudes have affected individuals' tendencies to support the EU enlargement (de Vreese and Boomgaarden 2005, but see Hobolt and Brouard 2011 on the French referendum on the EU constitution).

\section{The context of CEE immigration in the EU}

The general theoretical considerations and empirical findings summarized above need to be gauged to the specific case we study - immigration from CEE in the 'old' member states from Western and Souther Europe during the mid-2000s.

\subsection{Institutional setting}

Despite this initial wave of (labour) emigration from CEE during the early 1990s, the process of European integration of the post-communist countries presented a qualitatively new context for mobility within the continent. The burst in CEE immigration to the EU member states came only with the completion of the formal accession of the post-communist countries to the EU in 2004 for the Czech Republic, Estonia, Hungary, Latvia, Lithuania, Poland, Slovakia, and Slovenia (plus Cyprus and Malta), and 2007 for Bulgaria and Romania.

The moments of formal accession did not automatically imply free access to the labour markets in the 'old' member states which could impose temporary restrictions 
on the free movement of persons for the newcomers. Finland, Greece, Portugal, Spain, and Italy imposed two-year transitional periods during which restrictions applied, The Netherlands and Luxembourg three-year ones, and others - notably Germany and Austria - retained restrictions until 2011 (the maximum possible period). For Bulgarians and Romanians, the last barriers to the labour markets in the 'old' member states fell only at the end of 2013.

\subsection{East-West immigration: expectations and reality}

The scientific projections for the likely scale of post-Enlargement immigration commissioned by the EU institutions provided little cause for anxiety (for an overview see Heinz and Ward-Warmedinger 2006), but for many of the 'old' member states these projections proved too low. Ireland, the UK, and the Nordic countries in particular received quite substantial numbers of migrants from CEE, but also some Southern member states like Spain, Italy (Engbersen et al. 2013) and even Portugal were faced with unexpectedly high numbers of East Europeans post-Enlargement.

Gilpin et al. (2006) claim that in 2005 there were 245000 CEE migrants in the UK, one third of which had arrived during the previous year. In a recent study Friberg and Eldring (2013) estimate that 330000 citizens of the new member states moved to the Nordic countries between 2004 and 2011, with 20000 arriving in 2005 alone. In Germany 150000 have been registered in 2008 and 271000 in 2012 (excluding Bulgarians and Romanians). For The Netherlands, a conservative estimate puts the number at 165000 labour migrants from CEE states working regularly in the Netherlands as of 2008 (De Boom et al. 2010).

Although a comprehensive and reliable overview of the scale of CEE immigration after Enlargement seems impossible for the moment - the available comparative estimates provided via EUROSTAT are certainly underestimates - it is clear that the scale was big enough to make the CEE immigrants visible as a group, and to heighten fears of flooding by cheap labour. The scale of CEE immigration is certainly not unprecedented on the European continent after World War II, but what is perhaps new is the exclusive connection between the population movements and the process of European integration. While during the 1950s and 1960s millions of Italians, Spanish, Portuguese, Greek, Yugoslavian, and Turkish workers sought employment in Western Europe, the flows of labourers were regulated by bilateral agreements only, and it was in fact the host countries that actively sought migrant labour. But during the Eastern enlargement, labour migration was framed as an issue of free movement of persons within the common European Union which shifts both the responsibility and the blame for the migration flows. And the migration flows happened in a rather different economic climate than the growth years of the 1950s and 1960s.

\subsection{Types of East-West immigration}

Part of the reasons why the estimation of post-Enlargement migration flows is so difficult is that the types of migrants moving from CEE to the 'old' member states (and back) do not fit easily the existing statistical (and analytical) categories. There is a growing academic literature developing that tries to capture the new emerging types and forms of migration that escape the old dichotomies between temporary and permanent, legal and illegal, and low-skilled and high-skilled migration (see Engbersen et al. 2013). Notions like 'liquid migration', 'global nomads', 'circular migration', 'storks and hamsters' are being introduced in the academic discourse, but have not 
made their way to the statistical nomenclatures that keep track on immigration yet.

Most certainly, the official statistics on which we have to rely for the empirical analysis to measure the presence of CEE immigrants at the local level in four European countries are under-estimates of the total stock of people from CEE residing at any particular moment in these localities and are more likely to capture people who have settled for an extended period of time, have or seek legal employment, and are 'integrated' in the host societies to the extent that they are at least aware of the need for registration. Nevertheless, within countries the official figures should capture the relative distribution if not the absolute numbers of CEE immigrants. In sum, the numbers we have to rely on handicap the analysis towards not finding any relationship between immigration presence and the attitudes of the host populations.

For several additional reasons, the empirical context we focus on can be seen as a rather unlikely case to observe negative effects of immigration presence. First, the cultural distance between the European citizens on both sides of the Berlin Wall is certainly small compared to the distance between the 'native' population of Western Europe and the large groups of African and Asian immigrants that have taken residence in Europe since the 1960s. Second, many Western European societies have long experiences with immigration, so it is perhaps unlikely that any new arrivals can have additional impact. Third, and perhaps most importantly, the CEE countries were in the process of becoming full members of the EU. In the EU, the freedom of movement and work is a fundamental right, so labour migration within the Union should be viewed differently than labour migration from other countries.

\section{A theoretical model}

The numbers of immigrants from CEE who arrived in Western and Southern Europe after the fall of the Berlin Wall till the mid 2000s were substantial and the newcomers became publicly visible as a group in many of the 'old' member states. Moreover, their settlement has been uneven not only between different countries, but also inside the host countries as well. Consequently, we hypothesise that the effect of this immigration presence will vary not only between, but also within these states. Hence, our main hypothesis is that:

Hypothesis 1: At the regional level within countries, the more CEE immigrants present, the lower the average support for European integration among the local population.

The strength of this relationship itself, and not only the absolute level of Euroscepticism, would be expected to vary from one member state to another due to cross-national differences in how Enlargement and immigration are portrayed by national politicians and the media. Furthermore, as suggested by the existing literature reviewed above, economic conditions, like the level of unemployment, might also moderate the relationship across and within countries and over time as well.

The link between immigration presence and support for integration is supposed to be mediated mainly through a change in anti-immigration attitudes. It is conceivable, however, that the two are directly related as well. That is, the local presence of a large group of CEE immigrants can decrease support for the EU even if it does not increase xenophobic attitudes, but affects considerations, for example, about the relative economic costs and benefits of integration. 


\subsection{Putting it all together: a tentative model}

The theoretical considerations discussed above are summarized in the following causal graph (Figure 1). Arrows indicate hypothesized causal links, and the absence of arrows implies the lack of links between the variables. The graph summarizes the relevant causal assumptions we make and is useful for identifying the variables we have to include in the empirical analysis in order to isolate the effect of immigration presence on European integration attitudes. The dotted lines represent the hypothesized links which we want to establish. The supposed direction of the causal link is shown with a plus or minus sign (or a question mark if uncertain).

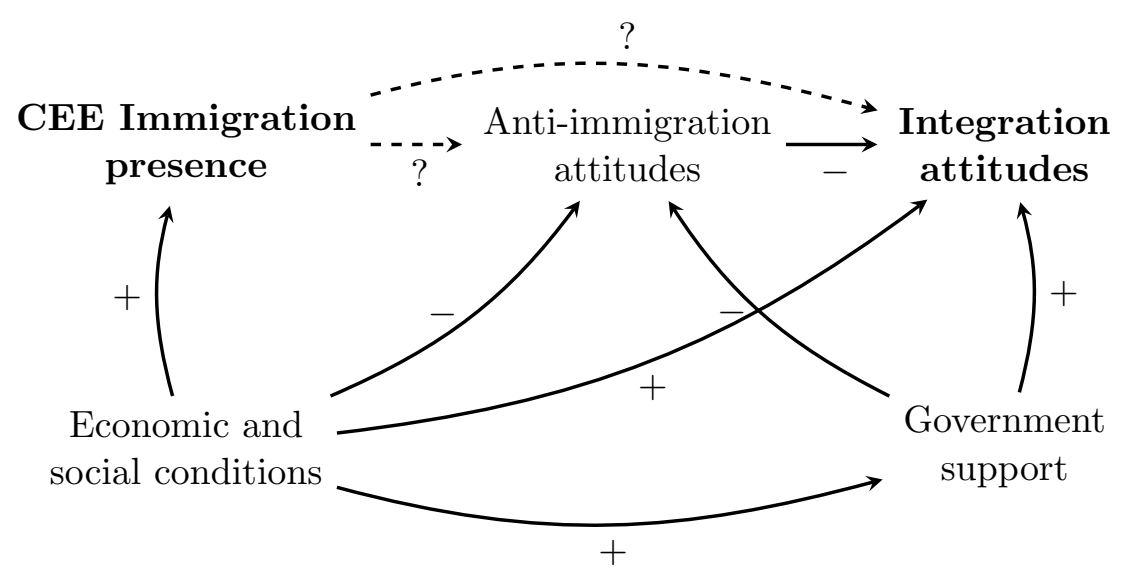

Figure 1: Causal diagram

Figure 1 includes the mediating influence of anti-immigration attitudes although this is not a variable we can measure in the analysis. Economic and social conditions are supposed to influence the settlement decisions of the immigrants, who would be attracted by more prosperous localities with lower unemployment and more highlyeducated population. But as these factors have also been shown to influence attitudes towards the EU, they become potential omitted variables that confound the main relationship we are interested in. Hence, we control for them in the empirical analysis, and we use the size of the pre-existing non-European immigrant community as an additional proxy for the attractiveness of a region.

Incumbent government support is a factor that we include in the models because of the specific setting of our empirical tests, namely the referendums on the European Constitution. Even if this variable does not influence immigration settlement patterns - hence, it is not a confounder - measuring it can help in the estimation of the main relationship we are interested in, because it is a strong predictor of the referendum vote, so controlling for it can take away additional variation in the outcome variable (EU support).

\section{$5 \quad$ Research design}

This section of the paper presents the research design including the level of analysis, the country selection, and the data sources and operationaliztaion. 


\subsection{Level of analysis}

The theoretical processes outlined in the previous section play out at the community (regional) level. While contact and attitudes are individual-level phenomena, we are interested in the impact of local immigration presence (outgroup size) - which is an aggregate-level phenomenon - on the average attitudes of the host communities. At the same time, the state is at a too high level of aggregation as a unit of analysis for our research purposes. We expect variation within states in the average attitudes in particular communities (regions), and we expect that the variation will be related to the size of local immigration presence. Therefore, the level of analysis for the empirical part of our study is defined as the (sub-national) region ${ }^{1}$.

To remind, our aim is not to test contact theory as such, but to establish how direct contact and the indirect effects of immigrant proximity affect attitudes towards European integration. Since the size of the local immigrant population is constant for all individuals living in the same region although individual contact may vary, the individual is not a proper unit of analysis for our purposes. Having individual-level data for the persons sampled within regions would allow for the testing of additional hypotheses (for example, whether within a region the individuals who have had direct contact with immigrants experience a different attitude change than those who only experience indirect effects), but we are not aware of any data source that contains individual-level data on contact with CEE immigrants and attitudes towards immigrants and European integration for the citizens of the EU member states from Western and Southern Europe.

While the appropriate level of analysis is aggregate and smaller than a state, it is difficult to define more precisely at which particular scale of regional aggregation the empirical study should be conducted. At smaller regional levels of aggregation for example, neighbourhoods - the direct contact effects will play a bigger role vis-ávis the indirect effects of immigration presence. But once the regional unit gets too big, the direct effects would almost completely disappear, the indirect effects of local immigration presence will get diluted, and the only indirect effects that would remain would be the nation-wide ones shaped by political discourse and national policies.

In any case, the precise choice of level of analysis is very much constrained by the available data. When having a choice, we have opted for the lowest level of aggregation possible. In effect, the level of analysis differs in the four countries we study, ranging from municipalities in The Netherlands (with a mean of 41, 000 and a maximum of 790, 000 inhabitants), to counties in Ireland (mean of 97, 000 and a maximum of 137, 000), to departments in France (mean of 669, 000 and a maximum of 2.6 million), to provinces in Spain (mean of 828, 000 and a maximum of 5.8 million). Details are available in Table 1. Overall, the relationship we are looking for would be more likely to be found at the smaller levels of aggregation.

\subsection{Country selection}

We study all countries for which we could obtain recent 1) reliable regional-level estimates of the presence of CEE immigrants, and 2) representative regional-level estimates of attitudes towards EU integration. In practice, the second requirement limits the available choice to the three countries that held referendums on the proposed EU constitution in 2005 - Spain, France, and The Netherlands (Luxembourg excluded

\footnotetext{
${ }^{1}$ Note that since we do not make any conclusions about the attitudes and behaviors of individuals in the analysis, our design is not subject to the problems of ecological inference which plague individual-level conclusions based on aggregate-level data
} 
due to its size), and Ireland, which held a referendum on the successor of the proposed Constitution - the Lisbon Treaty - in 2008. Other voting data, while available at different levels of aggregation, would not allow for isolating opinions towards the future course of European integration from other idealogical and political attitudes and orientations. The usual sources of data on attitudes towards integration and the EU - the multi-national Eurobarometer surveys - do not allow for the construction of representative regional-level aggregates (beyond the very large NUTS-2 level) from the individual data they provide.

Luckily, the four countries for which we happen to have data have all experienced substantial and reasonably-well documented levels of immigration from CEE (with a significant degree of within-country differences in where the immigrants settle) and represent a considerable range of attitudes towards EU integration, with the Spanish population being most EU-friendly, and the Dutch showing the least enthusiasm (at least for the Constitution).

\subsection{Data and operationalization}

In this subsection of the paper we will briefly describe the operationalization of the main variables used in the empirical analyses. Details are available in the Appendix accompanying the main text which also includes a table with descriptive statistics.

The outcome we model - support for European integration - is operationalized as the percentage of local support for the European Constitution/Treaty of Lisbon at the national referendums in 2005/8 [EU support]. While at these plebiscites the citizens expressed approval or disapproval for a particular document rather than for further European integration in the abstract, the two are strongly related, so that we can use the former as a proxy for the latter ${ }^{2}$. The national referendums on the Constitution were also embedded in local politics and, to a different degree in different states, have been used by citizens to express support or opposition to the governing parties (which supported the Constitution). Therefore, we include the support for the governing parties at the time of the Constitution in the region as a covariate in the analysis [government support $]^{3}$.

The main explanatory variable we are interested in is operationalized as the relative size of the local CEE immigration community. More precisely, we calculate the share of registered immigrants (as of 2005/8) from the ten CEE countries that joined the EU in 2004 and 2007 in a region from the total population of the region [CEE immigrants].

We use two variables to capture the possible confounding effects of economic and social conditions - unemployment and education levels in the region. For the precise definitions and data sources, see the Supplementary materials. In the case of The Netherlands, we also control for the income and average level of religiosity of the municipalities.

An important covariate we include in the analyses is the size of the pre-existing local non-European immigrant community [other immigrants]. The inclusion of this

\footnotetext{
${ }^{2}$ It is well established that many additional considerations, in addition to general attitudes towards the future of European integration, affected voting 'for' or 'against' the proposed Constitutional Treaty and the Treaty of Lisbon (see, among others, Lubbers 2008, Hobolt and Brouard 2011). For our purposes it is enough, however, that attitudes towards integration are still correlated with voting even if they are not the most powerful predictor of the vote. The fact that the vote is an imperfect proxy of the attitudes we are interested in makes it more difficult to find the hypothesized relationship in the data. To reduce what can be thought of as random measurement error due to additional predictors of the vote, we include measures of government support in the analysis.

${ }^{3}$ Note that since we are not interested in building a predictive model of the 'Yes' vote as such, but only in isolating the possible relationship between integration attitudes and immigration presence, we do not have to control for all possible predictors of voting at the referendums, but only for the ones that can be suspected to affect the level of immigration presence as well (confounders).
} 
variable serves a double purpose. First, it provides an additional indirect control for the economic and social attractiveness of a region. Second, it allows us to isolate the additional effect of the arrival of 'new' CEE immigrants from a possible effect of existing (non-European) immigration presence on anti-immigration attitudes and support for European integration.

\subsection{Method of analysis}

Our main empirical strategy for the identification of the effect of CEE immigration on European integration support is through conditioning - we build multivariate regression models in which the covariates included block the potential influence of the likely confounders. The remaining association between CEE immigration and EU support in the data can be interpreted in causal terms to the extent that we have successfully blocked all confounded paths between these two variables and we can rule out reverse causality (endogeneity).

We run the analyses within each country rather then pool the data from the four countries in a multilevel model, because there are considerable differences between the countries in the absolute levels of CEE immigration, attitudes towards European integration, and an additional set of possible confounders which would be very hard to control for, like the relative attractiveness of countries or the national-level salience of the immigration issue. Furthermore, the precise definitions of our covariates differ across countries which prohibits pooling the data. In any case, using four separate within-country analyses rather than one pooled multilevel model provides for a more stringent test of our hypotheses. The empirical results presented below are driven only by between-region within-country associations rather than cross-country differences for which a causal effect of immigration on EU support would have been much harder to identify given the many additional possible confounders.

For each country, we use a multivariate liner regression model to estimate the effect of CEE immigrants. Theory does not imply, strictly speaking, a linear form of the association between outgroup size and integration attitudes, so, as an alternative, we estimated generalized additive models (GAM) as well, which allow us to relax the linearity assumption. The GAM indicated deviations from linearity, but no systematic pattern. Given the relatively small number of observations, the GAM estimates are also rather sensitive. Therefore, we choose to focus on the empirical findings based on the more familiar linear multivariate regressions.

\section{Immigration and integration attitudes: em- pirical analysis}

Table 1 presents the estimates from the four country-level regressions. The table lists the coefficients, their standard errors, and levels of statistical significance. All variables have been z-transformed (centered to have a mean of zero and divided by their standard deviation), so the coefficients are directly interpretable as the expected standard deviation change in EU support for a standard deviation change in the share of CEE immigrants, Unemployment, etc. Thus, the relative size of the coefficients in Table 1 is also comparable across variables.

The regression coefficient for the size of local CEE immigrant presence is negative in Ireland, France, Spain, and The Netherlands. On average, net of other effects, regions with a higher number of $\mathrm{CEE}$ immigrants have expressed less support for 


\begin{tabular}{|c|c|c|c|c|}
\hline Variable & Ireland & France & Spain & The Netherlands \\
\hline \multirow[t]{2}{*}{ CEE immigrants } & $-0 \cdot 23^{*}$ & $-0.13^{*}$ & $-0 \cdot 11$ & $-0.08^{*}$ \\
\hline & $(0 \cdot 10)$ & $(0 \cdot 05)$ & $(0 \cdot 13)$ & $(0 \cdot 04)$ \\
\hline \multirow[t]{2}{*}{ Government support } & $0 \cdot 19^{*}$ & $0.22^{* * *}$ & $0 \cdot 33^{*}$ & $0.45^{* * *}$ \\
\hline & $(0 \cdot 09)$ & $(0 \cdot 06)$ & $(0 \cdot 14)$ & $(0 \cdot 04)$ \\
\hline \multirow[t]{2}{*}{ Unemployment } & $-0.59^{* * *}$ & $-0 \cdot 42^{* * *}$ & $0 \cdot 12$ & $0 \cdot 14^{* * *}$ \\
\hline & $(0 \cdot 09)$ & $(0 \cdot 06)$ & $(0 \cdot 14)$ & $(0 \cdot 04)$ \\
\hline \multirow[t]{2}{*}{ Other immigrants } & $0 \cdot 18$ & $0 \cdot 04$ & $0 \cdot 06$ & $0 \cdot 01$ \\
\hline & $(0 \cdot 13)$ & $(0 \cdot 07)$ & $(0 \cdot 12)$ & $(0 \cdot 05)$ \\
\hline \multirow[t]{2}{*}{ Education } & $0 \cdot 35^{* *}$ & $0 \cdot 64^{* * *}$ & $-0 \cdot 47^{* * *}$ & $0 \cdot 28^{* * *}$ \\
\hline & $(0 \cdot 12)$ & $(0 \cdot 07)$ & $(0 \cdot 12)$ & $(0 \cdot 03)$ \\
\hline \multirow[t]{2}{*}{ Income } & & & & $0 \cdot 39^{* * *}$ \\
\hline & & & & $(0 \cdot 04)$ \\
\hline \multirow[t]{2}{*}{ Religiosity } & & & & $-0 \cdot 83^{* * *}$ \\
\hline & & & & $(0 \cdot 10)$ \\
\hline Adjusted $\mathrm{R}^{2}$ & $0 \cdot 74$ & $0 \cdot 78$ & 0.54 & $0 \cdot 63$ \\
\hline Observations & 42 & 96 & 51 & 449 \\
\hline \multicolumn{5}{|c|}{ All variables z-transformed. Significance levels: $0<{ }^{* * *}<0.001<^{* *}<0.01<^{*}<0.05$} \\
\hline
\end{tabular}

Table 1: Results from linear regression models of EU support in four countries

the EU Constitution/Treaty of Lisbon in all four countries for which we have data. The association is statistically significant at the 5 percent level in three out of the four countries (Spain being the exception). The substantive size of the effect ranges between 0.08 (The Netherlands) and 0.23 (Ireland) which implies that one standard deviation increase in the share of CEE immigrants in the region decreases on average EU support in the region by approximately 1.5 percentage points in Ireland and 0.6-0.7 percentage points in the other three countries.

The lack of significance of the effect of CEE immigrants in the Spanish case is not really surprising given the very high absolute level of EU support in the country and the high level of aggregation - the Spanish provinces are on average the largest regional units used in our analyses. For the Irish case we replicated the analysis using data on the second referendum on the Treaty of Lisbon (2009) - the effect of CEE immigration presence remained negative ( $\mathrm{p}$-value $<0.10$ ).

The statistical models reported in Table 1 have reasonable fit (adjusted $\mathrm{R}^{2}$ between 0.54 and 0.78 ) and the effects of the included covariates are mostly in the expected directions. It is worth noting that the size of the pre-existing non-European immigrant community in the region is not negatively associated with EU support in any of the four countries - the estimated coefficients are positive and statistically insignificant. This indicates that it is specifically the new immigrants from CEE that influence the European integration attitudes of the host societies in Western and Southern Europe, and not the pre-existing burden of (non-Western) immigration as such.

The results of the reported statistical models indicate that immigration from the new member states has eroded support for integration among the citizens of the old member states. But it should be pointed out that the empirical results are sensitive to the exact specification of the models (covariates included, form of the association, 
etc.).

\section{Conclusion}

We set out to evaluate the impact of immigration from CEE on the support for further European integration expressed by the people in Western and Southern Europe. Our empirical analyses suggest that immigration has indeed undermined public support for integration. In all four countries we study, aggregate support for the European constitution is negatively associated with the number of CEE immigrants present in the region.

While our results are suggestive, we would caution against a strong causal interpretation of the findings. The models we employ try isolate the impact of CEE immigration conditional on a number of potential confounders. Nevertheless, given the complex web of relationships between the social, economic, and attitudinal variables we study and the relatively small number of observations each of our analyses is based on, one should see our conclusion about the possible causal link between immigration and integration as preliminary.

Obviously, more research is needed to probe the generalizability of our findings beyond the four countries we study. Other Western and Southern European states have also received substantial numbers of immigrants from CEE after EU Enlargement, and in many of these states support for Europe has dramatically declined within the same period. Whether the temporal coincidence is more than an accident of history remains to be determined, but our results suggest that there is a plausible set of causal arguments that links immigration and attitudes towards immigration and the EU.

A major difficulty for future research is the lack of representative local level data on the social and political phenomena discussed here. Recent EU legislative action might alleviate the problem of having reliable and comparable data on immigration levels at the local level and by country of origin. For obtaining local and regional level data on social attitudes (towards immigration and the EU) one could turn to the recently-popularized technique for estimating local level averages from national data (which is readily available) with the help of multilevel modeling and poststratification (Park et al. 2004).

The conclusions we offer concern the short-term effects of new immigration. Extending the research over longer time periods might uncover different and more subtle effects of varying immigration levels. Prolonged contact with the immigrants from the East might help forge a common European identity, but it could also provoke a parochial drive for national isolation.

At a more general level, our study sheds light on the inherent tension between deepening and widening of European integration. The Eastern Enlargement and the (still imperfect) freedom of movement and work it has brought to the people from Eastern Europe have widened tremendously the geographical scope of the union. But if indeed new immigration erodes support for integration, as our study suggests, the widening might indirectly put the brakes on further deepening of the European project.

At the same time, external events, like the financial crisis, as well as the internal dynamics of integration pose challenges for which deepening seems to be the only answer. How the EU is going to reconcile these conflicting pressures remains to be seen. One potential answer to the dilemma suggested by our study is to wait for better economic times which might loosen public antipathy towards immigration which in turn suppresses support for integration. 
It is more than a little ironic that the dream of free movement, work and settlement in Europe seems to be undermined precisely by its gradual realization. Economic migration from one part of the continent to another is not only conceivable but in fact necessary if the EU's economy is to be truly integrated. For many years after the creation of the single market, mass economic migration within old Europe remained only a theoretical possibility. But when the countries from the East joined, the possibility rapidly became a reality for many states in the West, and for some in the South, of the continent. And the reaction of the host societies has not been a very welcoming one. In fact, in response, societies in Western Europe might have turned against the dream of free movement itself.

\section{References}

Allport G W (1954) The nature of prejudice. Cambridge, MA: Perseus Books.

Azrout R, van Spanje J H P and de Vreese C H (2013) Focusing on differences? Contextual conditions and anti-immigrant attitudes effects on support for Turkeys EU membership, International Journal of Public Opinion Research 25(4): 480-501.

Barbulescu R and Beaudonnet L (2014) Protecting us, protecting Europe? Public concern about immigration and declining support for European integration in Italy, Perspectives on European Politics and Society 15(2): 216-37.

Blalock H (1967) Toward a theory of minority-group relations. New York and London: Wiley \& Sons.

Boomgaarden H G, Schuck A R T, Elenbaas M and de Vreese C H (2011) Mapping EU attitudes: Conceptual and empirical dimensions of Euroscepticism and EU support, European Union Politics 12(2): 241-66.

De Boom J, Weltevrede A, Snel E, Konrad T and Engbersen G (2010) Dutch SOPEMI report 2009. Migration and migration policies in the Netherlands 2009. Rotterdam: Risbo/Erasmus University

de Vreese C H and Boomgaarden H G (2005) Projecting EU referendums: Fear of immigration and support for European integration, European Union Politics 6(1): 59-82.

Della Posta D J (2013) Competitive threat, intergroup contact, or both? Immigration and the dynamics of front national voting in France, Social Forces 92(1): 249-73.

Deutsch K (1953) Nationalism and social communication. An inquiry into the foundations of nationality: MIT Press.

Engbersen G, Leerkes A, Grabowska-Lusinska I, Snel E and Burgers J (2013) On the differential attachments of migrants from Central and Eastern Europe: A typology of labour migration, Journal of Ethnic and Migration Studies 39(6): 959-81.

Fassmann H and Munz R (1994) European east-West migration, 1945-1992, International Migration Review 28(3): 520-38.

Friberg J and Eldring L (eds) (2013) Labour migrants from Central and Eastern Europe in the Nordic countries patterns of migration, working conditions and recruitment practices. Copenhagen: Nordic Council of Ministers.

Gilpin N, Henty M, Lemos S, Portes J and Bullen C (2006) He impact of free movement of workers from Central and Eastern Europe on the UK labour market: Department for Work and Pensions Working Paper No. 29.

Halla, M., Wagner, A.F. and Zweimller, J. (2012) Does Immigration Into Their Neighborhoods Incline Voters Toward the Extreme Right? The Case of the Freedom Party of Austria, CEPR Discussion Papers 9102. 
Heinz F F and Ward-Warmedinger M (2006) Cross-border labour mobility within an enlarged EU. Frankfurt am Main: European Central Bank.

Hobolt S and Brouard S (2011) Contesting the European Union? Why the Dutch and the French rejected the European constitution, Political Research Quarterly 64(2): 309-22.

Hooghe L and Marks G (2009) A postfunctionalist theory of European integration: From permissive consensus to constraining dissensus, British Journal of Political Science 39(01): 1-23.

Kuhn T (2012) Why educational exchange programmes miss their mark: Crossborder mobility, education and European identity*, JCMS: Journal of Common Market Studies 50(6): 994-1010.

Lubbers M (2008) Regarding the Dutch 'nee' to the European constitution: A test of the identity, utilitarian and political approaches to voting 'no', European Union Politics 9(1): 59-86.

Lubbers M and Jaspers E (2011) A longitudinal study of Euroscepticism in the Netherlands: 2008 versus 1990, European Union Politics 12(1): 21-40.

Luedtke A (2005) European integration, public opinion and immigration policy: Testing the impact of national identity, European Union Politics 6(1): 83-112.

Manevska K and Achterberg P (2013) Immigration and perceived ethnic threat: Cultural capital and economic explanations, European Sociological Review.

McLaren, L.M. (2003) Anti-immigrant prejudice in Europe: contact, threat perception, and preferences for the exclusion of migrants. Social Forces, Vol. 81, No. 3, pp. 90936.

McLaren L M (2012) The cultural divide in Europe: Migration, multiculturalism, and political trust, World Politics 64(02): 199-241.

Mudde C (2007) Populist radical right parties in Europe. Cambridge: Cambridge University Press.

Mundell R A (1961) A theory of optimum currency areas, American Economic Review 51(4): 657-65.

Park, D.K., Gelman, A. and Bafumi, J. (2004) Bayesian Multilevel Estimation with Poststratification: State-Level Estimates from National Polls.Political Analysis, Vol. 12, No. 4, pp. 37585.

Pettigrew T F (1998) Intergroup contact theory, Annual Review of Psychology 49: 65-85.

Putnam R D (2007) E Pluribus Unum: Diversity and community in the Twentyfirst century the 2006 Johan Skytte Prize Lecture, Scandinavian Political Studies 30(2): $137-74$.

Scharpf, F. (2013) Monetary Union, Fiscal Crisis and the Disabling of Democratic Accountability. In Schfer, A. and Streeck, W. (eds) Politics in the Age of Austerity (Cambridge: Polity Press), pp. 10842

Scheepers P, Gijsberts M and Coenders M (2002) Ethnic exclusionism in European countries - public opposition to civil rights for legal migrants as a response to perceived ethnic threat, European Sociological Review 18(1): 17-34.

Schlueter E and Scheepers P (2010) The relationship between outgroup size and anti-outgroup attitudes: A theoretical synthesis and empirical test of group threatand intergroup contact theory, Social Science Research 39(2): 285-95.

Schlueter E and Wagner U (2008) Regional differences matter: Examining the dual influence of the regional size of the immigrant population on derogation of immigrants in Europe, International Journal of Comparative Sociology 49(2-3): 153-73. 
Schneider S L (2008) Anti-immigrant attitudes in Europe: Outgroup size and perceived ethnic threat, European Sociological Review 24(1): 53-67.

Semyonov M, Raijman R and Gorodzeisky A (2006) The rise of anti-foreigner sentiment in European societies, 1988-2000, American Sociological Review 71(3): 42649 .

Semyonov M, Raijman R, Tov A Y and Schmidt P (2004) Population size, perceived threat, and exclusion: A multiple-indicators analysis of attitudes toward foreigners in Germany, Social Science Research 33(4): 681-701.

Sides J and Citrin J (2007) European opinion about immigration: The role of identities, interests and information, British Journal of Political Science 37: 477-504.

Silvia S J (2011) Is the Euro working? The Euro and European labour markets, Journal of Public Policy 31(3): 305-26.

Startin N and Krouwel A (2013) Euroscepticism re-galvanized: The consequences of the 2005 French and Dutch rejections of the EU constitution, JCMS: Journal of Common Market Studies 51(1): 65-84.

van Spanje J and de Vreese C (2011) So whats wrong with the EU? Motivations underlying the Eurosceptic vote in the 2009 European elections, European Union Politics 12(3): 405-29.

Wagner U, Christ O, Pettigrew T F, Stellmacher J and Wolf C (2006) Prejudice and minority proportion: Contact instead of threat effects, Social Psychology Quarterly 69(4): 380-90.

Zürn M and Checkel J T (2005) Getting socialized to build bridges: Constructivism and rationalism, Europe and the nation-state, International Organization 59(04): 104579 . 